\title{
cepead
}

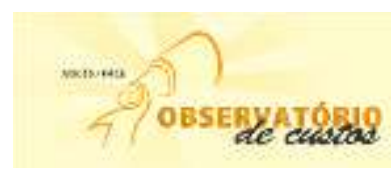

\section{A PARTICIPAÇÃo dOS PLANOS DE SAÚDE NOS ATENDIMENTOS MÉDICOS NO ESTADO DE SANTA CATARINA ${ }^{1}$}

\author{
PARTICIPACIÓN DE LOS PLANES DE SALUd EN CITAS MÉDICAS EN SANTA \\ CATARINA
}

\section{PARTICIPATION OF HEALTH PLANS IN MEDICAL APPOINTMENTS IN SANTA CATARINA}

\author{
LEANDRO DOS SANTOS BERNARDES \\ Unisul - Universidade do Sul de Santa Catarina \\ lbernardess@ig.com.br
}

TAISA DIAS

Unisul - Universidade do Sul de Santa Catarina

taisadias.adm@gmail.com

\author{
SIMONE SEHNEM \\ Unisul - Universidade do Sul de Santa Catarina \\ simonesehnem_adm@yahoo.com.br
}

\section{RESUMO}

Com o crescimento do mercado dos planos de saúde privado, a presente pesquisa consiste de um levantamento do tipo survey, realizado no período de 19/03/2013 a 15/05/2013, buscando identificar a representatividade dos planos de saúde nas agendas médicas no Estado de Santa Catarina. A coleta de dados se deu por meio de um questionário eletrônico respondido por 368 médicos em atividade no estado. O estudo foi construído levando em consideração o mercado emergente em decorrência da lacuna deixada pelo setor público que não consegue cumprir de forma eficiente suas atribuições básicas. Os resultados apontam para expressiva dependência das agendas médicas à planos de saúde, o que instala competição entre os operadores e distorções do papel do poder público que ao invés de prestar o serviço passa a regulá-lo.

Palavras-chaves: Serviços de saúde. Plano de Saúde. Saúde suplementar.

\section{ABSTRACT}

With the growth of the market for private health plans, this research consists of a survey-type survey, conducted from 19/03/2013 to 15/05/2013, seeking to identify the representation of health plans in the medical appointment book State of Santa Catarina. Data collection was done through an electronic questionnaire answered by 368 physicians practicing in the state. The study was constructed taking into account the emerging market due to the gap left by the public sector can't efficiently fulfill its basic tasks. The results show significant dependence on the agendas medical health plans, which installs competition between operators and distortions of the role of government that instead of providing the service starts to regulate it.

KEYWORDS: Health services. Health Plan. Health administration.

\section{RESUMEN}

Con el crecimiento del mercado de planes de salud privados, esta investigación consiste en un estudio de tipo encuesta, realizada a partir de 19/03/2013 a 15/05/2013, buscando identificar la representación de los planes de salud en las agendas médicas Estado de Santa Catarina. La recolección de datos se realizó a través de un cuestionario electrónico respondida por 368 médicos que ejercen en el estado. El estudio se construyó teniendo en cuenta el mercado emergente debido al vacío dejado por el sector público no puede cumplir eficazmente sus

\footnotetext{
${ }^{1}$ Submetido em 23 de junho de 2013. Aceito em 10 de outubro de 2013. O artigo foi avaliado segundo o processo de duplo anonimato e avaliado pelo editor. Editores responsáveis: Márcio Augusto Gonçalves e Lucas Maia dos Santos. Reprodução parcial ou total e trabalhos derivativos permitidos com a citação apropriada da fonte.
} 
funciones básicas. Los resultados muestran una dependencia significativa en las agendas de los planes de salud médicos, que instala la competencia entre los operadores y las distorsiones de la función del Estado que, en lugar de la prestación del servicio se inicia a regularlo.

PALABRAS CLAVE: Servicios de salud. Plan de Salud. Salud complementário.

\section{INTRODUÇÃO}

A prestação de serviços de saúde no Brasil constitui-se em uma das mais importantes atribuições do Estado, quando se refere às políticas públicas, haja vista que encontra-se disciplinado na Constituição da República Federativa do Brasil de 1988, em seu artigo 196 que "a saúde é um direito de todos e um dever do Estado". Porém, a garantia deste direito aos cidadãos torna-se uma tarefa complexa, pois segundo Censo realizado em 2010 pelo Instituto Brasileiro de Geografia e Estatística (IBGE, 2013), o Brasil é um país de dimensões continentais que abriga uma população de 190.732.694, distribuída em 5.565 municípios, o que dificulta a atuação do gestor público e que por consequência torna o acesso dos serviços aos cidadãos um caminho longo e demorado.

Tais dificuldades encontradas pelo gestor público estão ligadas ao modelo de ação estatal em que prevalecem os fundamentos da teoria da burocracia, defendida por Weber (1999), onde através da formalização as organizações atingiriam o mais alto grau de eficiência, mas quando aplicados de forma excessiva acabam por gerar distorções e vulnerabilidades, constituindo seu agente de ineficiência para executar suas atribuições de acordo com as exigências e necessidades da sociedade.

Neste sentido, ineficiência do governo na prestação dos serviços de saúde possibilita que esta demanda seja atendida pelo setor privado, no qual se instala um novo e atrativo mercado, onde a competição acentua-se ao ponto de necessitar a intervenção governamental no sentido de regular e regulamentar as atividades dos operadores, criando para esta finalidade a ANS - Agência Nacional de Saúde Suplementar.

Não obstante, sob a ótica de que as empresas necessitam contar com profissionais qualificados em seus quadros funcionais, já que o desdobramento das estratégias empresariais quase sempre passa por ações que são desempenhadas por pessoas, os empregadores dos diversos segmentos do mercado, reconhecem as dificuldades de acesso ao sistema de saúde público, uma vez que ao adotarem estratégias de retenção de recursos humanos, ofertam aos empregados um pacote de benefícios onde o plano de saúde constitui importante diferencial, aquecendo ainda mais a competitividade entre os planos de saúde privados, que partem para disputa de maior participação na cobertura do mercado, de modo a reduzir seus custos e sinistralidade. Esta competição sob a luz de Porter, (1999) faz com que os agentes busquem estratégias para posicionar-se no mercado, reagindo às pressões do mesmo e posicionando-se de forma defensiva ou ofensiva o que torna-se o braço do gestor público na regulação do mercado outra atividade complexa e ineficiente.

Em consequência disto, amplia-se o acesso da população aos serviços de saúde no âmbito privado, impactando diretamente na demanda para os profissionais da medicina e de serviços de suporte ao diagnóstico e ao tratamento das enfermidades que esta população, agora com acesso aos serviços de saúde, eventualmente venha ser acometida. Ao mesmo tempo, elevam-se os custos assistenciais dos empregadores que buscam alternativas através dos planos de autogestão (aqueles cuja administração é realizada pelo departamento de recursos humanos da empresa empregadora).

Contudo, não basta disponibilizar o plano de saúde. É necessário que este atenda as expectativas e necessidades dos empregados, o que ao contrário pode causar um efeito rebote, gerando insatisfação do empregado com o empregador, inclusive comprometendo a 
motivação e a produtividade na empresa.

Para tanto, sabe-se que a prestação dos serviços de saúde implica também em profissionais médicos satisfeitos com as condições de trabalho e remuneração, bem como com o relacionamento que os mesmos têm com os planos de saúde através das quais prestam seus serviços, o que pode influir na participação dos planos de saúde nas agendas médicas.

Neste cenário, emerge a seguinte pergunta de pesquisa: como se constitui a participação das operadoras de plano de saúde na agenda dos profissionais médicos em atividade no estado de Santa Catarina?

Diante disto, o presente artigo tem por objetivo geral discutir a representatividade das operadoras de plano de saúde nas agendas dos profissionais médicos em atividade no estado de Santa Catarina, o qual será atendido através dos objetivos específicos que seguem:

a) Evidenciar o percentual de médicos que atendem pacientes através de planos de saúde;

b) Verificar quais planos de saúde apresentam maior participação nas agendas dos médicos;

c) Identificar qual o modelo do plano de saúde mais aderente junto aos profissionais da medicina;

d) Refletir sobre o papel do estado como agente garantidor da prestação de serviços de saúde à sociedade.

Para tanto, utilizou-se uma pesquisa survey, caracterizada como de abordagem qualitativa e quantitativa, pois a mesma objetivou verificar a natureza das relações entre as variáveis bem como observar o volume destas relações, onde a possibilidade de generalização dos dados torna-se relevante para a academia, uma vez que possibilita verificar empiricamente uma teoria central que sustentou, além de permitir aos empregadores a identificação dos planos de saúde que possuem maior participação e aderência junto à classe médica catarinense, de modo que possam contribuir para maior satisfação de seus empregados ao disponibilizar estes serviços em seu pacote de benefícios. Já para os profissionais da medicina representa oportunidade de verificar a concentração ou dispersão de suas agendas, identificando o grau de dependência de sua atividade a uma ou outra operadora, bem como o impactos disto nos seus resultados financeiros.

O estudo torna-se relevante também, pela possibilidade de expansão do setor, pois conforme Tabnet (ANS, 2013), os planos de saúde privados são utilizados por apenas 21,6\% da população do Estado de Santa Catarina, característica favorável a novos entrantes, o que amplia a competitividade e gera maior necessidade de controle por parte do estado.

Para sustentar as análises realizadas, encontra-se no capítulo 2 a revisão de literatura que cerca o tema. Já o capítulo 3, explicita o detalhamento da metodologia empregada na elaboração desta pesquisa. Na sequencia, o capítulo 4 traz as análises e os resultados que estas possibilitaram, assim como as conclusões possíveis.

\section{REFERENCIAL TEÓRICO}

Através da literatura disponível, buscou-se o referencial teórico para fornecer suporte aos temas utilizados para responder a pergunta de pesquisa. Os assuntos abordados nesta seção consistem em caracterizar a gestão dos serviços de saúde no Brasil ao longo do tempo; contextualizar a saúde suplementar, bem como a competitividade instalada no setor.

\section{GESTAO DA SAÚDE NO BRASIL}

A saúde é sem dúvidas um bem maior para o ser humano e seu cuidado, uma preocupação permanente da sociedade, tanto que encontra-se disposto na constituição 
brasileira em seu artigo196 que a "a saúde é direto de todos e dever do Estado, garantido mediante políticas sociais e econômica que visam a redução do risco de doença e de outros agravos e ao acesso universal e igualitário às ações a promoção, proteção e recuperação". Políticas estas que de alguma forma sempre foram atribuições do estado, mas que somente são ratificadas na década de 1980 com a promulgação da nova Carta Magna.

Sob a ótica de Dias (2012), é possível entender que na antiguidade o Estado era alheio à dimensão social, voltando-se suas preocupações centrais com a administração do patrimônio, que confundia-se com o patrimônio dos governantes, e que gerava distorções entre seu papel efetivo e aquilo que os ocupantes do poder julgavam ser. Nesta época, os serviços de saúde eram privilégios dos poucos que dispunham de recursos próprios para tal finalidade e o restante da população deveria ser tratado nos pequenos hospitais que existiam e que de acordo com Scliar (1987), contavam com poucos recursos do governo, que só os repassavam porque precisavam isolar estes cidadãos da sociedade, para evitar o contágio das enfermidades, funcionando com um depósito de doentes.

Com o desenvolvimento econômico do país houve a necessidade de se olhar para questões sanitárias, com o objetivo de prevenção de doenças, o que pode caracterizar a primeira interferência do governo acerca deste tema, quando por volta de 1920 é organizada a diretoria geral de saúde pública no Brasil, e posteriormente, em 1931, a criação do Ministério de Educação e de saúde (IYDA, 1993). Ligado a este novo ministério, cria-se o IAP'S Instituto de Aposentadoria e Pensão, que era subsidiado por descontos compulsórios dos trabalhadores assalariados e por recursos do Estado, para além de gerar caixa para manter aposentados, também tinha que financiar a assistência à saúde, que mais tarde, em 1966, passa a ser concentrado em uma única administração, recebendo o nome de INPS - Instituto Nacional de Previdência Social, que concentrava a arrecadação de todos os descontos, compulsórios, dos salários dos trabalhadores, ampliando substancialmente as receitas (COHN; ELIAS, 1996).

Até então, a assistência médica individual era um serviço disponível a uma pequena parcela da população, aos mais abastados que possuíam condições e não dependia da mão do governo, fato que passa a incomodar os órgãos representativos dos trabalhadores, que entendiam haver necessidade de disponibilizar este acesso a todos os trabalhadores, dando início ao INAMPS, um sistema em que possibilitava médicos e clínicas particulares se conveniarem ao governo para prestação dos serviços a população, constituindo o SUDS Sistema Unificado e Descentralizado de Saúde, caracterizado como um convênio com o INAMPS, o que na visão de Cohn e Elias (1996) eram utilizados como instrumentos de manobras políticas, reforçando as características burocráticas do modelo de gestão instalado, que reforçava a busca pelo controle centralizado gerando ações pouco efetivas.

Resultado das transformações do papel da administração pública ao longo do tempo, o Sistema Único de Saúde - SUS, que se conhece hoje, somente foi criado a partir da Constituição Federal de 1988, onde a esfera federal passa a regular os recursos, que são transferidos aos municípios para administração e manutenção dos programas, caracterizando a necessidade do estado descentralizar o poder para realmente se tornar eficiente naquilo que é sua função essencial.

O SUS tem como finalidade eliminar a desigualdade na assistência à saúde da população, desta forma, constituindo a obrigação do estado de prestar atendimento público a todos os cidadãos sem nenhuma forma de cobrança, independente da condição sócioeconômica do mesmo. Para tanto, conforme dados divulgados pelo Ministério da Saúde, em 2010, o sistema contava com 63 mil ambulatórios, seis mil hospitais e 367 mil leitos, nas três esferas governamentais, cada qual com comando, responsabilidades e competências distintas.

Todavia, administrar uma estrutura desta grandeza e ramificação, pode constituir-se em dificuldades para prestar atendimento de saúde à população no tempo e localidade que 
esta necessitar, pois segundo Weber (1998), a organização burocrática, preocupada com atribuições de eficiência em mais elevado grau, acaba por gerar disfunções que recaem sobre o indivíduo. Apoiando as afirmações de Weber, percebe-se na obra de Dias (2012), que mesmo diante de todas as transformações ocorridas nas funções do Estado, a função arrecadadora é aquela em que este agente atinge o mais alto grau de eficiência, uma vez que as ações de pagamento dos tributos emanam da sociedade (descentralizada) para uma entidade central.

Sendo assim, aquela assistência médica diferenciada que outrora era privilégios de poucos, ainda predomina ampliando-se as possibilidades para a iniciativa privada que passa a ofertar estes serviços através de um sistema denominado de saúde suplementar, pois constituise de casos cujo acesso ao serviço não se dá pelo poder público.

\section{SAÚDE SUPLEMENTAR NO BRASIL - PLANOS DE SAÚDE}

Não obstante ao que ocorre em outros setores, o mercado de saúde suplementar encontra-se em extrema competitividade no Brasil, haja vista o surgimento de novas operadoras, que necessitam da adesão dos médicos para prestarem serviços através delas e da confiança dos usuários finais para sua contratação, onde as estratégias se diferenciam muito das adotadas pelo setor público, que na visão de Fensterseifer (1999), passa pela maneira como a organização se relaciona com seu ambiente, contemplando o estabelecimento de métodos e planos de ação, para o atendimento das necessidades de seu principal cliente.

Neste sentido, muito embora a assistência à saúde, como atividade econômica permeie a sociedade ao longo tempo, conforme Cordeiro (1984), é a partir do governo de Juscelino Kubitschek, com a entrada das indústrias automobilísticas, que os planos de saúde começam a se assemelharem aos modelos que existem hoje, sendo utilizados pelos empregadores como atrativos de retenção de mão de obra.

Porém, só em 1988, após o movimento de Reforma do Estado, com a Constituição Federal que este assunto é legitimado. O poder público manteve o dever de regular e fiscalizar o setor, conforme disposto no artigo 197 da referida Constituição: "são de relevância pública as ações e serviços de saúde, cabendo ao poder público dispor, nos termos da lei, sobre sua regulamentação, fiscalização e controle, devendo sua execução ser diretamente ou através de terceiros e, também, por pessoa física ou jurídica de direito privado", o que fundamenta a criação da Agência Nacional de Saúde Suplementar - ANS, que conforme Lei nº 9.961, de 28 de janeiro de 2000, é a instância reguladora e fiscalizadora do setor.

Segundo a ANS, existem diversas modalidades de planos de saúde, dentre as quais destacam-se:

- Plano de saúde individual - o consumidor contrata um plano de saúde para e/ou familiares, diretamente junto a operadora que escolher.

- Plano de saúde coletivo - quando quem contrata o plano de saúde para o cliente é o seu empregador, órgão de classe ou associação.

- Plano de saúde coletivo de autogestão - aquele em que a rede é contratada pelo departamento de recursos humanos de uma empresa para atender a seus funcionários, sendo estes custos por ela administrados.

Com o mercado regulamentado, este setor passou a ser disciplinado, inclusive em relação à lista de procedimentos e valores dos mesmos, ampliando a competitividade, uma vez que o consumidor está mais exigente, ciente de seus direitos e que existe um padrão a ser respeitado pela operadora. Já através desta regulamentação, algumas operadoras de planos de saúde passam a receber isenções fiscais, especialmente aquelas constituídas por associações ou cooperativas de profissionais da medicina, o que não deixa de ser uma forma de 
financiamento parcial pelo Estado, que deveria proporcionar maior cobertura da população. Neste sentido, também existem situações em que o próprio Estado é o contratante do serviço privado, disponibilizando para a população em atendimentos específicos, através de convênios ou cooperação técnica.

A ótica da contratação de um plano de saúde suplementar está alicerçada no pagamento antecipado pela eventual contraprestação do serviço quando da sua necessidade e que em decorrência da impossibilidade do ser humano prever os males que lhe afetarão e ao não utilizar $100 \%$ dos serviços em todos os momentos, mas paga um pouco todo mês, os custos dos procedimentos ficam mais acessíveis. Neste sentido, consiste uma das preocupações da agência reguladora, tomar ações para que as operadoras não adotem demasiadas restrições de uso, impossibilitando a utilização. Tais restrições de uso sugerem que o antídoto proposto pelo estado ao regular a atividade, acaba possibilitando aos planos de saúde privado um importante instrumento de competição, que na visão de Sehnem; Lazzarotti; Bandeira-De-Mello (2010), remetem ao modelo Porteriano de competição.

\section{METODOLOGIA}

Para esta pesquisa delimitou-se os médicos atuantes no estado de Santa Catarina e com registro profissional vinculado ao Conselho profissional da categoria no Estado, que conforme dados divulgados no website do CFM - Conselho Federal de Medicina, totalizam uma população de 13.221 médicos, dos quais 8.000 foram convidados a responder ao questionário através de endereço eletrônico específico disponibilizado para ACM - Associação Catarinense de Medicina, sendo utilizado o modelo abaixo em destaque na Figura 2.

Figura 1: Levantamento da população a ser pesquisada

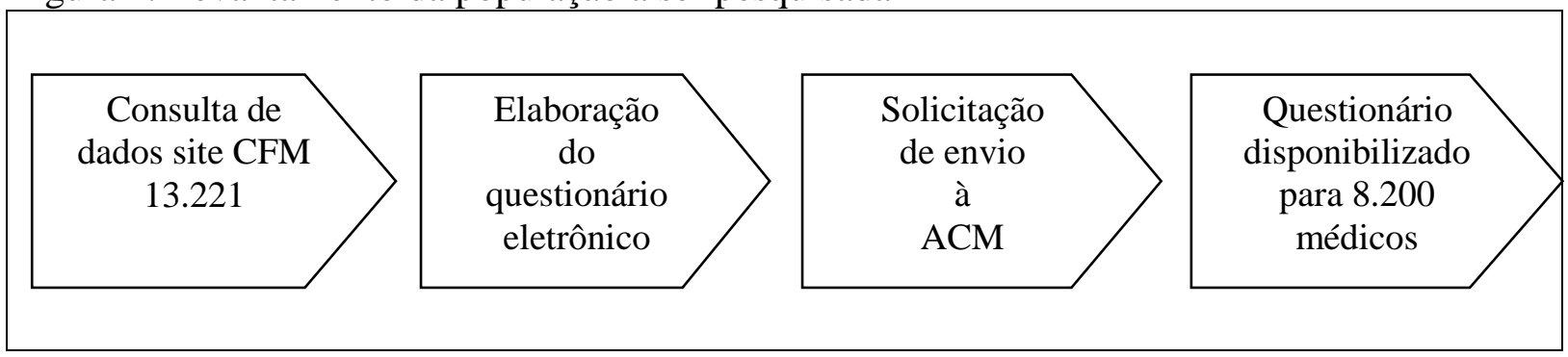

Fonte: Elaboração dos autores (2013)

O estudo ocorreu no período de 19/03/2013 à 15/05/2013, partindo da definição da amostra que foi obtida através da aplicação da fórmula estatística indicada para populações formadas por grandes números, considerando um nível de confiança de $95 \%$, que é explicitada a seguir:

$$
n=\frac{N \cdot Z^{2} \cdot p \cdot(1-p)}{Z^{2} \cdot p \cdot(1-p)+e^{2} \cdot(N-1)}
$$

onde: $\mathrm{n}$ - amostra calculada; $\mathrm{N}$ - tamanho da população; $\mathrm{Z}$ - variável normal padronizada associada ao nível de confiança; p - verdadeira probabilidade do evento; e - erro amostral tolerável;

Aplicada a fórmula evidenciada acima, resultou como 368 o número ideal de amostras capazes de caracterizar e generalizar as pesquisas para aquela população. 
Isto posto, a presente pesquisa possui uma abordagem quantitativa e qualitativa que visa relacionar o volume de atendimentos realizados através de operadoras de planos de saúde e com as estratégias de posicionamento utilizadas pelas operadoras, pois conforme encontrase em Roesch (2007), a abordagem qualitativa e quantitativa podem ser utilizadas em conjunto para avaliação formativa e de resultados, sendo ambas abordagens complementares.

Já em relação ao enfoque do artigo, trata-se de uma pesquisa exploratória, pois proporcionará maior conhecimento sobre o tema, e que de acordo com Gil (2002) proporciona maior familiaridade com o problema e seu principal objetivo é o aprimoramento de ideias que estimulem a compreensão do fato estudado.

Com relação ao procedimento metodológico, trata-se de um levantamento ou survey, que na visão de Vergara (2005) é um levantamento realizado para coletar informações sobre práticas e opiniões de uma população específica com vistas a possibilitar a generalização da mesma através das variáveis selecionadas.

A coleta de dados foi realizada através da ferramenta de pesquisa denominada Survey Monkey para questionários online. $\mathrm{O}$ mesmo foi estruturado com duas questões para identificação do respondente, uma questão fechada de simples escolha, uma questão aberta de múltipla escolha e uma questão aberta para comentários gerais e opcionais, totalizando assim 5 questões, identificadas no apêndice I. Os questionários foram disponibilizados em um link eletrônico, através de um convite enviado ao médico por correio eletrônico, no período de 19/03/2013 a 02/04/2013, onde obteve-se 577 respondentes, atingindo-se uma amostra superior ao nível de confiança aplicado de 95\%, que determinava uma amostra de 368 respondentes.

Os dados coletados foram agrupados de acordo com as opções disponíveis para respostas e como se buscava identificar a representatividade destas na totalidade dos respondentes, utilizou-se tratamento estatístico simples da amostra, relacionando as variáveis de forma dependente. Já as respostas obtidas através do espaço destinado para comentários espontâneos, foram agrupadas em 6 categorias de acordo com a análise de conteúdo, que na visão de Carmo-Neto (1996), pode ser operacionalizada a partir de documentos escritos, sonoros, imagens, entre outros, identificando através destas as mudanças de atitudes dos sujeitos envolvidos.

Desta forma, todos os dados coletados foram tabulados em planilha Excel, gerando gráficos que possibilitaram as análises e os resultados, compondo o modelo demonstrado na Figura 3.

Figura 2: Framework da pesquisa

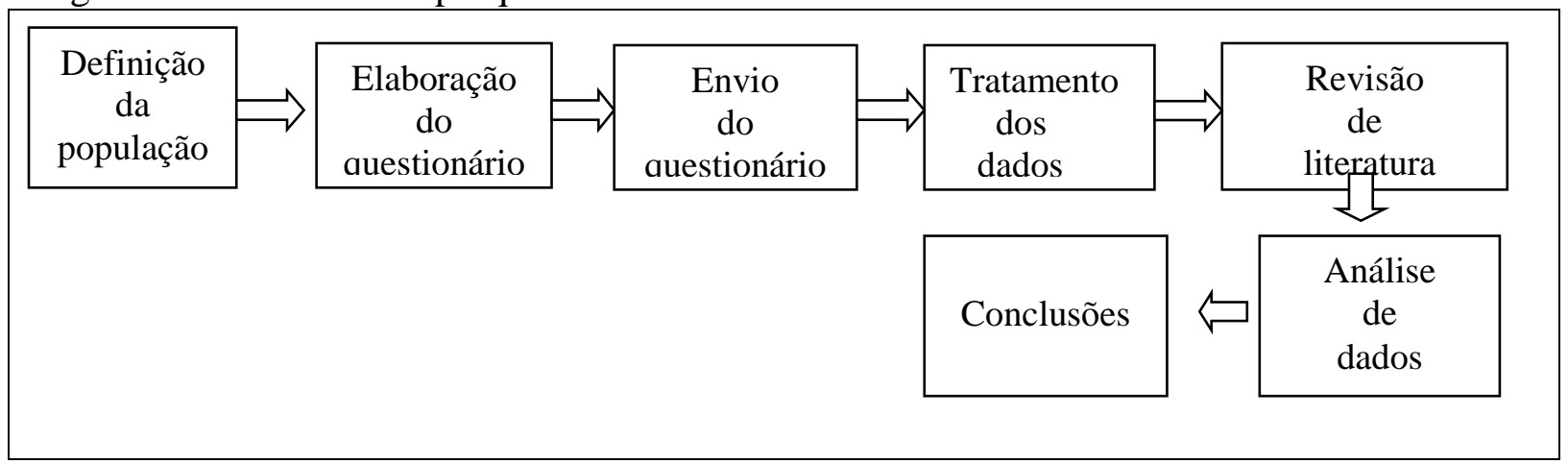

Fonte: Elaboração dos autores (2013)

De posse dos dados tabulados em conformidade com o esquema de trabalho proposto na figura 3, foi possível efetuar as análises e encontrar os resultados dispostos no capítulo 4, destacando-se como limitação da pesquisa somente os atendimentos médicos realizados 
através de intermediação de planos de saúde, não considerando que os mesmos profissionais que prestam serviços por planos de saúde podem ter algum tipo de vínculo com o sistema de público de saúde.

\section{RESULTADOS E CONCLUSÕES}

Ao analisar os dados coletados, foram elaborados os gráficos que seguem, possibilitando visualizar e ilustrar mais facilmente as variáveis pesquisadas através do questionário eletrônico.

\section{MÉDICOS QUE ATENDEM POR CONVÊNIO}

Conforme demonstrado no Gráfico $1,74,2 \%$ dos médicos consultados atendem pacientes através de planos de saúde, totalizando 428 profissionais. Apenas $25,8 \%$ dos médicos declararam que não atendem via planos de saúde, que totalizam 149 profissionais.

Grafico 1: Médicos que atendem pacientes através de plano de saúde

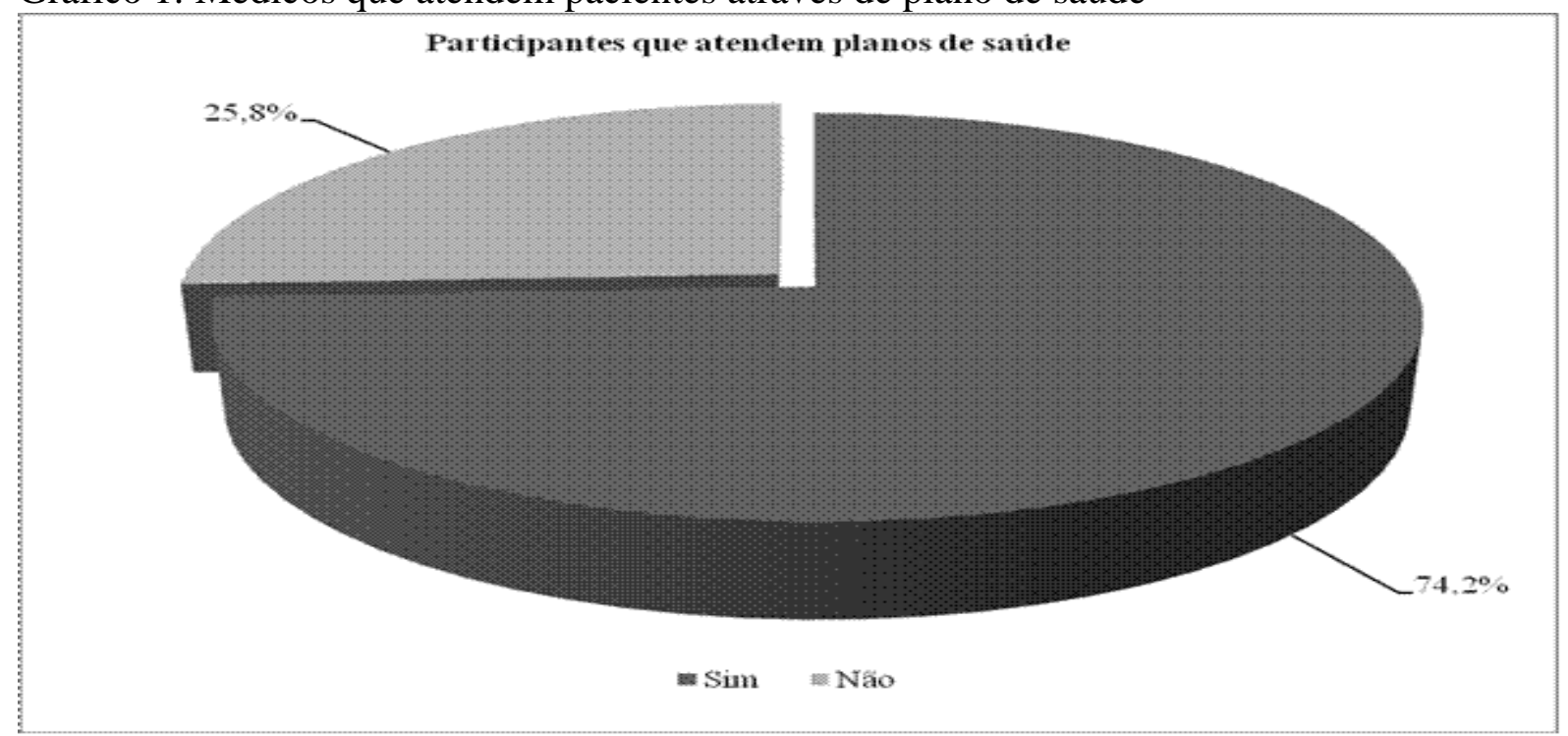

Fonte: Dados primários (2013)

De forma a aprofundar as análises, faz-s necessário evidenciar as operadoras com maior representatividade nos atendimentos médicos no estado de Santa Catarina, buscando junto aos médicos que atendem através de planos de saúde, qual a participação de cada plano de saúde nos atendimentos que fazem.

\section{PARTICIPAÇÃO DAS OPERADORAS NAS AGENDAS MÉDICAS}

Dentre os médicos respondentes que prestam serviços através de planos de saúde suplementar, evidencia-se na tabela 1 , os 10 planos de saúde mais representativos nas agendas dos médicos catarinenses. 
Tabela 1: Participação das Operadoras nas Agendas Médicas

\begin{tabular}{|c|c|c|c|c|c|c|c|c|c|c|c|c|c|c|c|c|c|c|c|c|c|c|}
\hline \multirow{3}{*}{ Operadora } & \multicolumn{20}{|c|}{ Participação das Operadoras nas Agendas Médicas } & \multirow{3}{*}{ Soma } & \multirow{3}{*}{$\%$} \\
\hline & \multicolumn{2}{|c|}{$10 \%$} & \multicolumn{2}{|c|}{$20 \%$} & \multicolumn{2}{|c|}{$30 \%$} & \multicolumn{2}{|c|}{$40 \%$} & \multicolumn{2}{|c|}{$\mathbf{5 0 \%}$} & \multicolumn{2}{|c|}{$60 \%$} & \multicolumn{2}{|c|}{$\mathbf{7 0 \%}$} & \multicolumn{2}{|c|}{$80 \%$} & \multicolumn{2}{|c|}{$90 \%$} & \multicolumn{2}{|c|}{$100 \%$} & & \\
\hline & $\mathbf{N}^{\circ}$ & $\%$ & $\mathbf{N}^{\circ}$ & $\%$ & $\mathbf{N}^{\circ}$ & $\%$ & $\mathbf{N}^{\circ}$ & $\%$ & $\mathbf{N}^{\circ}$ & $\%$ & $\mathbf{N}^{\circ}$ & $\%$ & $\mathbf{N}^{\circ}$ & $\%$ & $\mathbf{N}^{\circ}$ & $\%$ & $\mathbf{N}^{\circ}$ & $\%$ & $\mathbf{N}^{\circ}$ & $\%$ & & \\
\hline Unimed & 17 & 3,97 & 16 & 3,74 & 26 & 6,07 & 41 & 9,58 & 44 & 10,28 & 31 & 7,24 & 46 & 10,75 & 44 & 10,28 & 27 & 6,31 & 16 & 3,74 & 308 & 71,96 \\
\hline SC Saúde & 56 & 13,08 & 55 & 12,85 & 34 & 7,94 & 6 & 1,40 & 9 & 2,10 & 2 & 0,47 & 1 & 0,23 & 0 & 0,00 & 2 & 0,47 & 1 & 0,23 & 166 & 38,79 \\
\hline Agemed & 92 & 21,50 & 22 & 5,14 & 5 & 1,17 & 1 & 0,23 & 0 & 0,00 & 1 & 0,23 & 1 & 0,23 & 0 & 0,00 & 0 & 0,00 & 0 & 0,00 & 122 & 28,50 \\
\hline Cassi & 79 & 18,46 & 4 & 0,93 & 4 & 0,93 & 1 & 0,23 & 1 & 0,23 & 0 & 0,00 & 0 & 0,00 & 0 & 0,00 & 0 & 0,00 & 0 & 0,00 & 89 & 20,79 \\
\hline Geap & 57 & 13,32 & 6 & 1,40 & 1 & 0,23 & 0 & 0,00 & 0 & 0,00 & 0 & 0,00 & 0 & 0,00 & 0 & 0,00 & 0 & 0,00 & 0 & 0,00 & 64 & 14,95 \\
\hline $\begin{array}{l}\text { Outros } \\
\text { planos }\end{array}$ & 31 & 7,24 & 17 & 3,97 & 7 & 1,64 & 2 & 0,47 & 1 & 0,23 & 2 & 0,47 & 3 & 0,70 & 1 & 0,23 & 0 & 0,00 & 0 & 0,00 & 64 & 14,95 \\
\hline Eletrosul & 49 & 11,45 & 3 & 0,70 & 0 & 0,00 & 1 & 0,23 & 0 & 0,00 & 0 & 0,00 & 0 & 0,00 & 0 & 0,00 & 0 & 0,00 & 0 & 0,00 & 53 & 12,38 \\
\hline $\begin{array}{l}\text { Correios } \\
\text { Saúde } \\
\end{array}$ & 44 & 10,28 & 0 & 0,00 & 0 & 0,00 & 0 & 0,00 & 0 & 0,00 & 0 & 0,00 & 0 & 0,00 & 0 & 0,00 & 0 & 0,00 & 0 & 0,00 & 44 & 10,28 \\
\hline $\begin{array}{l}\text { Saúde } \\
\text { Caixa } \\
\end{array}$ & 39 & 9,11 & 3 & 0,70 & 1 & 0,23 & 0 & 0,00 & 1 & 0,23 & 0 & 0,00 & 0 & 0,00 & 0 & 0,00 & 0 & 0,00 & 0 & 0,00 & 44 & 10,28 \\
\hline Assefaz & 36 & 8,41 & 1 & 0,23 & 0 & 0,00 & 0 & 0,00 & 0 & 0,00 & 0 & 0,00 & 0 & 0,00 & 0 & 0,00 & 0 & 0,00 & 0 & 0,00 & 37 & 8,64 \\
\hline $\begin{array}{l}\text { União } \\
\text { Saúde } \\
\text { Jaraguá do } \\
\text { Sul }\end{array}$ & 11 & 2,57 & 0 & 0,00 & 2 & 0,47 & 1 & 0,23 & 1 & 0,23 & 1 & 0,23 & 0 & 0,00 & 0 & 0,00 & 0 & 0,00 & 0 & 0,00 & 16 & 3,74 \\
\hline
\end{tabular}

Fonte: Dados Primários (2013)

Na composição da tabela 1, estabeleu-se como corte para ingresso na tabela, os planos cujo volume de respostas positivas para atendimentos foram inferiores a 16 pacientes. Também importante ressaltar a expressiva participação atribuída para outros planos, ou seja, aqueles atendimentos que foram realizados através de algum plano de saúde não vinculado à região geográfica de Santa catarina ou através de convênios diretos entre empresas e profissionais liberais.

\subsection{CATEGORIZAÇÃO DOS COMENTÁRIOS FEITOS PELOS RESPONDENTES}

Com a finalidade de ampliar as informações pesquisadas, o questionário disponibilizou um espaço para que os respondentes manifestassem alguma outra contribuição que não foi prevista no questionário. Para facilitar a visualização destes comentários, os mesmos foram agrupados de acordo com o conteúdo do mesmo em 7 grupos conforme o quadro abaixo.

Quadro 1 - Categorização dos comentários observados pelos respondentes

\begin{tabular}{|c|c|c|c|c|c|}
\hline Grupo 1 & Grupo 2 & Grupo 3 & Grupo 4 & Grupo 5 & Grupo 6 \\
\hline $\begin{array}{c}\text { Posicionamento da } \\
\text { classe }\end{array}$ & Remuneração & $\begin{array}{c}\text { Valorização } \\
\text { profissional }\end{array}$ & $\begin{array}{c}\text { Desempenho do } \\
\text { profissional }\end{array}$ & $\begin{array}{c}\text { Restrições de } \\
\text { uso ao paciente }\end{array}$ & $\begin{array}{c}\text { Mudar regras de } \\
\text { atendimento }\end{array}$ \\
\hline 15 & 74 & 24 & 2 & 6 & 8 \\
\hline
\end{tabular}

Fonte: Dados primários (2013).

Grupo 1 Posicionamento da classe: Solicitam posicionamento e ações mais efetivas das entidades que representam a classe médica, no sentido de modificar a relação existente entre operadoras e prestadores, bem como melhorar a remuneração através destas intervenções.

Grupo 2 Remuneração: A grande insatisfação dos participantes é em relação à remuneração paga pelas operadoras para os procedimentos e consultas médicas, classificando-a como inapropriada e indigna, atrasando repasses e gerando glosas sem motivação. 
Grupo 3 Valorização profissional: Sentem-se desvalorizados pelas operadoras, que os vê como adversários e não como parceiros, muito embora também se encaixe no grupo 2 (remuneração).

Grupo 4 Desempenho do profissional: Este grupo faz críticas aos próprios profissionais, indagando se os mesmos estão realmente fazendo a sua parte de forma ética e decente.

Grupo 5 Restrições de uso ao paciente: grande demora para autorizar procedimentos e exames médicos, o que muitas vezes agrava a doença e as condutas a serem adotas a posterior.

Grupo 6 Mudar regras de atendimento: Defendem a ideia de que as consultas deveriam ser pagas de forma particular e que somente os exames, procedimentos e hospitais deveriam ser cobertos.

Dentre as manifestações coletadas encontra-se evidencias de um grande descontentamento dos profissionais médicos com a remuneração recebida e a falta de valorização de seu trabalho pelos planos de saúde, que aliadas as restrições de uso ao paciente, caracterizam a visão econômica que os planos de saúde possuem desta atividade.

\section{DISCUSSÃO DOS RESULTADOS}

Através da presente pesquisa, pode-se constatar que um elevado percentual $(74,20 \%)$ de médicos catarinenses prestam serviços através dos planos de saúde, o que caracteriza expressiva importância na vida profissional e financeira destes, onde a Unimed está presente em 71,86\% das agendas, seguida do plano destinado aos funcionários públicos SC SAÚDE participando em 38,79\%, em sequencia vem AGEMED com 28,50\%, CASSI com 20,79\%, GEAP com $14,95 \%$ e CORREIOS SAÚDE com 12,38\%.

Cabe destacar que os planos CASSI, GEAP E CORREIOS SAÚDE, fazem parte do Grupo Unidas, que administra estes planos na categoria de autogestão, e que ao serem agrupados possibilitam evidenciar que o plano de autogestão do conglomerado Unidas ocupa $48,12 \%$ das agendas dos médicos que atendem através desta. Neste sentido, a pesquisa aponta uma preferência importante por parte das empresas de grande porte na adoção deste sistema de assistência à saúde para os trabalhadores, o que tende a implicar em profissionais preparados para administrar este modelo de negócio, que agora vem para dentro da organização. Nesta ótica, além do setor público não cumprir com eficiência seu papel como garantidor de serviços básicos, onera em custos adicionais os meios produtivos do setor privado que necessitam gerir os serviços por eles mesmos contratados que outra era responsabilidade de governo.

Em relação ao plano SC SAÚDE, um plano de autogestão exclusivo para funcionários públicos que figura em segundo lugar entre os planos que mais ocupam as agendas médicas, revela um dado segundário importante, que suscita a dúvida: porque o próprio governo decide disponibilizar um plano de saúde para seus servidores ao invés de incentivar o uso dos serviços que ele disponibiliza a população? Seria este fato, o reconhecimento do governo que o acesso à saúde pública de qualidade é algo ineficiente? Por que financiar tais benefícios ao invés de utilizar destes recursos para melhorar a estrutura de sua própria rede prestadora? Respostas efetivas para estas questões não são possíveis de serem fornecidas com os dados coletados, muito embora assemelha-se aos construtuos trabalhados pela área de marketing e 
endomarmarketing remetendo a falta de confiança para indicar aquilo que a própria empresa produz para o mercado de fora às pessoas que estão no mercado de dentro.

Figurando no topo da ocupação das agendas está a Unimed, que constitui-se como uma cooperativa de trabalho dos médicos, com atuação nacional e administração descentralizada em diversas regionais, que em Santa Catarina, são coordenadas pela Unimed Federação SC. Sendo então uma cooperativa, os médicos, ao prestarem serviços através desta, deveriam ter suas possibilidades de remuneração ampliadas pois são como se fossem sócios da organização, dado que não foi objeto de estudo da presente pesquisa. Contudo, percebeu-se nas informações comunicadas no website da cooperativa, uma abordagem mercadológica mais agressiva, voltada para busca de novos clientes e pela manutenção da posição alcançada nas agendas médicas e um incentivo para utilização dos serviços disponibilizados pela rede própria, ou seja, unidades compostas por médicos contratados para a prestação de serviços ao invés de deixar de livre escolha do cliente, suscitando descaracterização de personalidade jurídica específica - cooperativa.

Neste sentido, a competitividade deste novo mercado gerado por uma ineficiência do setor público, conforme estudos de Porter (1989), à luz do trabalho de Sehnem; Lazzarotti; Bandeira-De-Mello (2010), implica que os operadores adotem artifícios processuais para manter uma posição estratégica no mercado, aplicando barreiras a novos entrantes ou tornando mais agressivas as existentes. Porém, ao trazer a tona o cenário pesquisado, verificase que este papel acaba por ser feito pelo setor público, que é o agente regulador do sistema através da ANS, preservando os agentes já instalados e estimulando entre eles novas distorções no modelo gerencial.

Através das manifestações espontâneas, que foram agrupadas no quadro n1, percebese um certo descontentamento dos profissionais da medicina com as operadoras de planos de saúde, especialmente relacionado a remuneração recebida, seguido das restrições impostas à atividade médica complementar (diagnóstico e tratamento), o que representa para as operadoras oportunidade de avaliar e discutir a remuneração dos prestadores de serviços e sob esta ótica a operadora Unimed, como tem a maior participação nas agendas pode ser caracterizada como a mais implicada nesta questão, mesmo não tendo sido este o objeto desta pesquisa.

A pesquisa permite evidenciar ainda que os respondentes esperam um papel mais atuante das entidades que os representam ensejando a importância destas nos processos de negociação entre as operadoras e os prestadores, caracterizando um descontentamento e desgastamento nas relações entre os planos de saúde e os profissionais médicos, gerando informações importantes para as entidades de classe.

Através deste estudo, verifica-se que na ausência do estado em uma atribuição que é legitimamente sua, cria um mercado amplo e complexo, e que também não supre as necessidades da população, permitindo ainda a instalação de problemas de outra ordem, como por exemplo, econômica e trabalhista. Constata-se isto através das manifestações dos médicos em relação a remuneração recebida, que aliadas a representatividade dos planos de saúde nas agendas médicas, constituem uma relação quase que de emprego. Neste mesmo contexto, ao evidenciar que alguns planos de saúde beneficiam-se com isenções fiscais, tributos que deixam de ingressar ao Estado para retorno na prestação dos serviços, sob a luz de uma população crítica, entende-se que paga-se duas vezes pelo serviço, uma para que o Estado atenda o seu papel para aqueles que conseguem acessar e outra vez quando necessitam utilizar serviços da rede privada.

\section{CONSIDERAÇÕES FINAIS}


O objetivo da presente pesquisa foi atendido, ao passo que possibilitou através de uma amostra significativa, conhecer e discutir a representatividade dos das operadoras de planos de saúde nos atendimentos realizados por médicos no Estado de Santa Catarina.

Estas discussões, aludidas pelas tipologias genéricas de Porter, representam importante contribuição às operadoras de plano de saúde, pois possibilitam a verificação do posicionamento estratégico adotado e sua real representatividade nas agendas médicas, permitindo a revisão de processos de trabalho, de comunicação, de remuneração, entre outros, para ampliar sua participação nos atendimentos médicos, o que por consequência implica em novos usuários aderindo a estas operadoras, possibilitando maior efetividade no seu desempenho e aumento de receita operacional.

Aparece ainda como uma contribuição tímida, mas direcionada ao governo, sobre a necessidade de se repensar os serviços públicos de atenção à saúde, pois ao adotar um plano de autogestão para o funcionalismo, sugere um descrédito ao seu próprio serviço.

O trabalho possibilita também para todas as organizações que buscam conceder aos seus empregados ou assemelhados um plano de saúde como componente do pacote de benefícios, pois evidencia aqueles planos que possuem mais aderência junto aos profissionais da medicina.

A pesquisa teve como limitação, somente relações com operadoras devidamente registradas junto a ANS - Agência Nacional Saúde Suplementar, mesmo sabendo-se da existência de convênios regionais que não se enquadram nesta categoria, como por exemplo, os convênios entre empresas e clínicas específicas, o que é considerado como conduta não ética.

Ao finalizar esta pesquisa, recomenda-se a investigação dos objetos que não foram alvos desta, mas que de alguma forma ampliariam as conclusões, como a satisfação dos médicos em relação ao relacionamento com as operadoras, bem como para a remuneração percebida. Sugere-se ainda, pesquisar a percepção ou satisfação do cliente final quando seu atendimento médico é prestado através de planos de saúde.

\section{REFERENCIAS}

AGENCIA NACIONAL DE SAÚDE SUPLEMENTAR (ANS). Disponível em: <http://www.ans.gov.br/>. Acesso em: 01 set. 2013.

BANDEIRA-DE-MELLO, Rodrigo; LAZZAROTTI, Fábio; SEHNEM, Simone. Uma análise longitudinal da utilização do paradigma Porteriano no Brasil. In BBR (Brazilian Business Reviw), Vitória-ES, maio-ago/2010.

BOWDITCH, J; BUONO, A. Elementos de comportamento organizacional. São Paulo: Livraria Pioneira Editora, 1992.

CARMO-NETO, Dionísio Gomes. Metodologia científica para principiantes. 3. ed. Salvador: American World University Press, 1996.

CONSELHO FEDERAL DE MEDICINA (CFM). Disponível em: <http://portal.cfm.org.br/>. Acesso em: 19 mar. 2013.

COHN, Amélia \& ELIAS, Paulo Eduardo. Saúde no Brasil: políticas e organizações de serviços. São Paulo, Cortez Editora, 1996. 
CORDEIRO, H. As empresas médicas: as transformações capitalistas da prática médica. Rio de janeiro: Graal, 1984.

DIAS, Taisa. Governança Pública: uma concepção teórico-analítica aplicada no governo do Estado de Santa Catarina a partir da implantação das Secretarias de Desenvolvimento regional. 356f. Tese (Doutorado em Administração) - Programa de Pós-graduação em Administração. Universidade Federal de Santa Catarina, Florianópolis, 2012.

FENTERSEIFER, J. E.; GALESNE, A.; LAMB, R. Decisões de Investimentos da empresa. São Paulo: Atlas, 1999.

GIL, A. Como elaborar projetos de pesquisa. 4. ed. São Paulo: Atlas, 2002.

INSTITUTO BRASILEIRO DE GEOGRAFIA E ESTATÍSTICA (IBGE). Disponível em: <http://www.ibge.gov.br/home/estatistica/populacao/censo2010/>. Acesso em: 02 set. 2013.

IYDA, Massako. Cem anos de saúde pública: a cidadania negada. São Paulo: UNESP, 1994. MINISTÉRIO DA SAÚDE. Disponivel em: <http://portalsaude.saude.gov.br>. Acesso em: 10 set. 2013.

PORTER, M. E. Estratégias Competitivas Essenciais: on competition. Rio de janeiro: Campus, 1999.

ROBBINS, S. Comportamento organizacional. Tradução Técnica: Reynaldo Marcondes. 9. ed. São Paulo: Prentice Hall, 2002.

ROESCH, S. Projetos de estágio e de pesquisa em administração. 2. ed. São Paulo: Atlas, 1999.

SCLIAR, Moacyr. Do mágico ao social: a trajetória da Saúde Pública, Porto Alegre: L\&PM Editores, 1987.

VERGara, Sylvia C. Projetos e Relatórios de Pesquisa em Administração. 6 ed. São Paulo: Atlas, 2005.

WEBER, Max. Economia e sociedade: fundamentos da sociologia compreensiva. Brasília: Universidade, 1999. 
APÊNDICE I - QUESTIONÁRIO ELETRÔNICO 


\section{CRM (opcional)}

*2. Informe seu município

*3. Você atende algum plano de saúde ?

$\bigcirc \operatorname{sim}$

Nลå

Clique no botão "Próximo" para continuar com a pesquisa 


\section{PLANOS DE SAÚDE}

4. Qual(is) planos de saúde você atende ? Informe o percentual de ocupação da agenda e o nível de satisfação com o plano

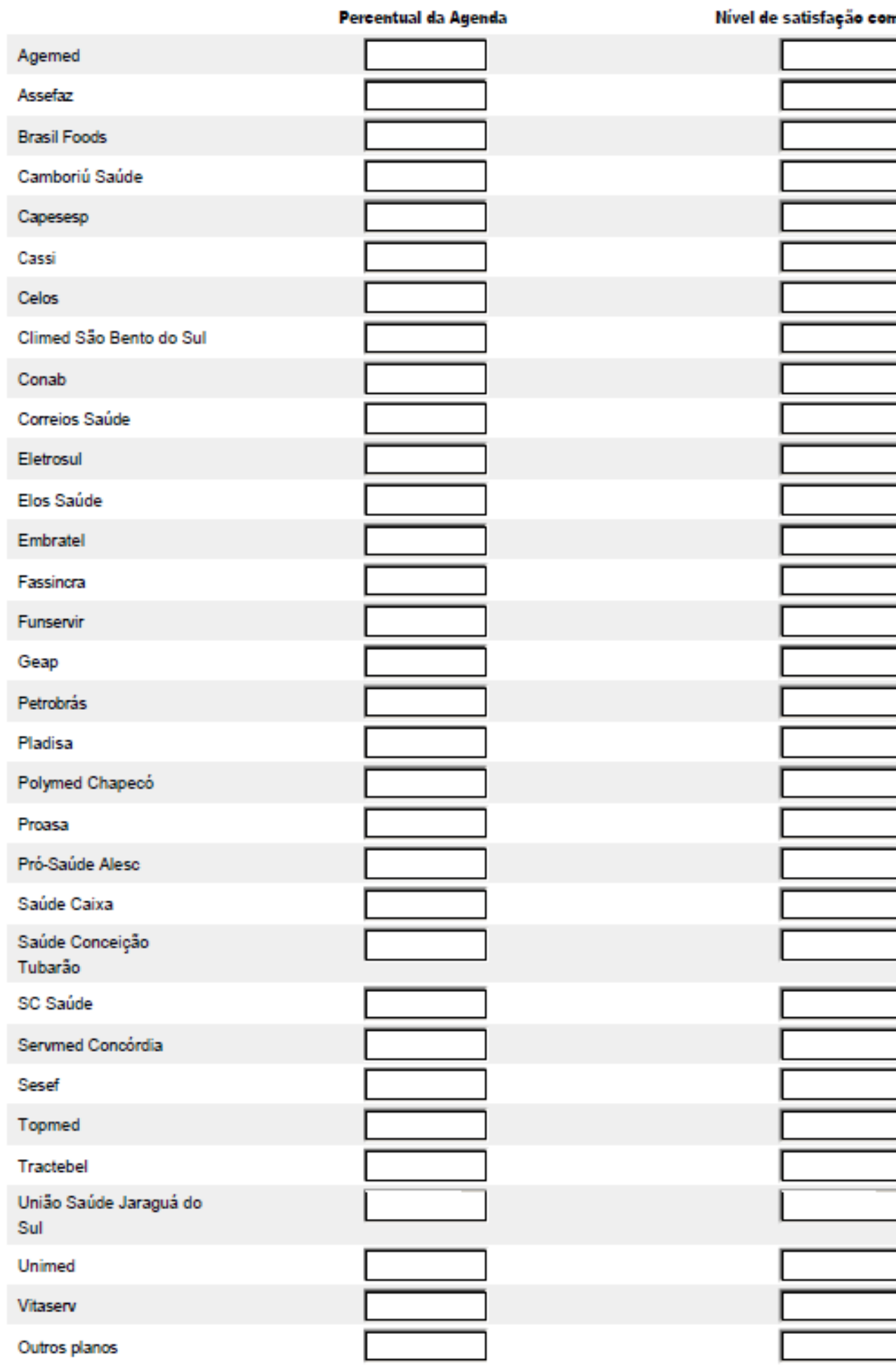

Clique no botão "Próximo" para continuar a pesquisa. 


\section{COMENTÁRIOS}

\section{Deixe seu comentário}

च

Clique no botăo "Concluido" para finalizar o questionário. 